\title{
Endothermy of organisms and subcellular mechanisms of thermogenesis
}

\begin{abstract}
Different ways of thermogenesis in the organism of warm-blooded organisms were considered in the review. Previous views on thermogenesis were based on the idea of low efficiency of biological processes. Subsequently it was demonstrated experimentally a fairly high efficiency of these processes. Otherwise, there would be no cold-blooded organisms and all animals were warm-blooded. At present specific mechanisms of thermogenesis are described. Uncoupling proteins (UPC) are isolated from the inner membrane of mitochondria, which increase the proton leakage of membranes, reducing the efficiency of the respiratory chain. Membrane anion-translocators also participate in proton leakage, which as a whole can increase the basal metabolism from 20 to $40 \%$. In another group of studies on mitochondria, a greater number of oxidative substrates were used. The results showed the existence of coupled and uncoupled mitochondria. The nativity of the latter was tested on isolated rat cardiocytes. Uncoupled respiration is significantly (up to 10 times) higher in mitochondria of endotherms than one of ectotherms and it can cause maintenance of the warm-bloodedness.
\end{abstract}

Volume 3 Issue 6 - 2018

\section{BA Niyazmetov, RN Akhmerov, KT Almatov, SO Mirzakulov, UZ Mirkhodjaev}

National University of Uzbekistan, Uzbekistan

\begin{abstract}
Correspondence: BA Niyazmetov, National University of Uzbekistan, Universitetskaya street, Tashkent, Uzbekistan, Tel +998903169537, Email physiolagist0107@gmail.com
\end{abstract}

Received: June 30, 2017 | Published: November 30, 2018

\section{Introduction}

It is generally known that mammals and birds are warm-blooded, and they are able to maintain such a state is not only in comfort, but in low and high temperature conditions. These circumstances, in all probability, were the prerequisite for the development of ideas about the existence of an organism of warm-blooded special heat generating system. Currently, it was accumulated a lot of material in this direction, which shows that heat production is determined by subcellular specialized mechanisms. It possesses various activities that differs significantly in phylogenetically different classes of vertebrates, in ontogenesis of mammals and birds at various states of an organism. Therefore, warm-blooded animals were allocated to a separate group possessing a high metabolism and support constant and high (about $36^{\circ} \mathrm{C}-40^{\circ} \mathrm{C}$ ) body temperature. The other group includes cold-blooded animals with low metabolism and changeable body temperature. To classify animals according to temperature status in modern literature it is widely used a term of "warm-blooded and cold-blooded", "homoeothermic and poikilothermic", "ectothermic and endothermic" animals. In practice, these groups are terms often used interchangeably although they have different meaning. We will also use them in unequivocal terms, although we mainly use a term of "ectothermia and endothermia". Differences in the level of metabolism between endo-and ectothermic organisms on average in 10 times, but in some cases it reaches up to 100 or more times. ${ }^{1-10}$ This comparison shows that maintaining of the endothermic state is achieved by a high cost. Possible, up to $90 \%$, and sometimes most of the metabolism is spent only on heat production to maintain the endothermic state of the body. Krogh ${ }^{11}$ is one of the first to notice lower metabolic rate in cold-blooded animals compared to the warmblooded. However, it took a long time to fully clarify the question about the difference between cold and warm-blooded organisms in metabolism and heat production.

In poikilothermic animals, unlike warm-blooded, metabolism depends on external conditions and may increase as the ambient temperature. In this case, accordingly, body temperature of cold- blooded can increase. In many cases the study of metabolism in cold-blooded is performed at optimum temperature of these animals. However, the results of such studies difficult to compare with those obtained for the warm-blooded as body temperature of animals is very different (in cold-blooded - about $20^{\circ} \mathrm{C}$, in warm-blooded about $37^{\circ} \mathrm{C}$ ). In consideration of this circumstance special studies of ectothermic animals at body temperature of $35-37^{\circ} \mathrm{C}$ were carried out. ${ }^{8}$ Their metabolism in these conditions differs about 10 times the level of metabolism of endothermic animals. It should also be noted that the intensity of metabolism of endothermic and ectothermic organisms decreases with increasing of body weight, though the tilt of the regression curve is approximately the same for these groups of animals. ${ }^{11-13}$ Dependence of metabolism on body weight is recognized as generally valid for warm and cold-blooded ${ }^{12}$ although a discussion has been conducted on its individual aspects to date. ${ }^{14}$ As described above, at comparison of cold-blooded with warm-blooded one must strictly consider the equality of their weight. In intensity of heat production endothermic and ectothermic animals vary in 5-10 times at the same temperature of their body ${ }^{8,15,16}$ at the optimum body temperature in cold-blooded $\left(20^{\circ} \mathrm{C}\right)$, they differ in $40-50$ times at $10^{\circ} \mathrm{C}$ of cold-blooded it differs approximately 100 time. ${ }^{8}$

Some investigations focus on the analysis of the energy cost of locomotion (energy consumption to per unit of movement speed $\mathrm{kg}$ of body weight) in the endothermic and ectothermic animals. According to the obtained data energetic cost locomotion in 2-10 times higher in endothermic than the ectothermic animals. As it can be seen from the above, the most significant difference of ectothermic animals from the endothermic ones is the ability of the first to expend considerably less energy to vital functions in peace and during activation of physiological processes. Therefore, based on the research of cold-blooded, vital activity seems energetically non-wasteful process. However, at consideration of warm-blooded isolated from cold-blooded, providing of vital functions seem paired with large power consumption. In the evolution of organisms, apparently, it can happened some changes in energy supply of basic functions, in particular, appearance of new energetic function in organism - providing warm-bloodedness. 
This circumstance could be the main cause of qualitative difference between endo and ectothermic animals in metabolism intensity. Physiological research of ecto-and endothermic animals served as a prerequisite for the development of the biochemical basis of thermogenesis. As a result, several biochemical views on origin of endothermy of organisms have been proposed.

\section{Effectiveness of the respiratory chain functioning and thermogenesis}

For a long time among the researchers there was a very popular point of view about low efficiency of energetic reactions in tissues as source of thermo production. On the basis of the data on the value of the standard free energy of ATP hydrolysis $(\Delta \mathrm{G})$, many researchers believed that roughly half of the energy of substrates oxidation in the synthesis of ATP in the mitochondria is dissipation the form of heat, and energy-dependent processes, recycling ATP, dissipate about another half of the remaining energy portion. Total energy losses for heat production would be about $70-80 \%$ of the initial energy of substrate oxidation. Only about $20 \%$ of the energy is stored in useful biological processes. ${ }^{17-24}$

As definition of free energy $\Delta G$ has shown content of ATP/ADP and phosphate in tissue, its value is much higher than the standard free energy of ATP hydrolysis and approximately corresponded to the values of ${ }^{13-16} \mathrm{kcal} / \mathrm{M}$ of ATP. ${ }^{18,20-31}$ These results indicate that the organization of cellular energetic system adapted to maintain a high level of free energy of ATP hydrolysis in tissues. At cellular values of ATP hydrolysis energy (13-16kcal/M) and reactants equilibrium level, the effectiveness of the respiratory chain, i.e. efficiency can be over $80 \%$. At present, researchers don't consider the synthesis and hydrolysis of ATP as an important source of thermogenesis. It should also be remembered if these processes occur in cold-blooded organisms that would be contradict to the conception of low efficiency of biological processes.

\section{The role of protein biosynthesis in thermogenesis}

It has been investigated high activity of protein synthesis in warmblooded organisms as the main factor of energy expenditure. In consideration of high energy of hydrolysis of peptide bonds in proteins (about $4 \mathrm{kcal}$ on per mole), Racker ${ }^{21}$ suggested the possibility of usage of functioning cell to $90 \%$ of the total energy of metabolism to the protein synthesis. In this connection, studies have been conducted to assess the energy value of the biosynthesis. On the basis of the account of accumulation of a growing body mass and changes of the level of basal metabolism it was found that the process of biosynthesis is responsible for the use of a small proportion of energy metabolism, i.e., $2-3 \%{ }^{32,33}$ The use of an inhibitor of protein synthesis to a warmblooded organism showed that under conditions of basal metabolism is suppressed to a small (to $5 \%$ ) value. ${ }^{34}$

\section{The role of $\mathrm{Na}$, K-ATPase}

A number of researchers, based on the experimental results, come to the conclusion that $40-50 \%$ of the energy of basal metabolism is spent to the functioning of Na, K-ATPase. ${ }^{35-42}$ However, according to the calculations of Van Rassum ${ }^{42}$ the share of transport-conjugated respiration in liver slices is not $40 \%$ as considered Ismail-Beigi, et al. ${ }^{38,39}$ but only about $3-6 \%$ of the total energy expenditure of tissue. Roughly the same size (2-6\%) energy consumption of Na, K-ATPase is given in other works. ${ }^{43-46}$ It is shown that the respiration rate in mice tissues 2-5 times higher than reptiles, while ouabain-sensitive part of respiration, associated with the operation of $\mathrm{Na}, \mathrm{K}-\mathrm{ATPase}$ in mouse tissues 4-9 times higher than in reptiles. ${ }^{15}$

\section{Heat production and the complexity of vertebrate organization}

Barton and Edholm ${ }^{47,48}$ believe that the warm-blooded animals is linked to the complexity of the organization and that maintaining of this organization requires certain power expenditure. However, the basal metabolic level and tissue respiration in large vertebrates is lower than that of small ones, although the organization of the first is higher. In consideration of these findings, Dolnik ${ }^{16}$ and SchmidtNielson ${ }^{9}$ express the opinion of the small dependence of the intensity of metabolism in the body of the level of organization of animals.

\section{Substrate (futile) cycles and thermogenesis}

According to conception of Newskholm ${ }^{49,50}$ an obligatory element of metabolic regulation must be "substrate cycles". Their regulatory efficiency, on theoretical considerations, much higher than the allosteric form of regulation. However, it is necessary to constantly expend of energy in the form of ATP. At present there are the following major "substrate cycles": I) phosphofructokinase/ fructosodi phosphatase cycle (PFK/ FBP); 2) the triglyceride fatty acid cycle. Newsholm et al. ${ }^{49}$ noted that "substrate cycle PFK/FBP at its maximal work is able to recycle about $10 \%$ of cellular ATP. In real terms, this value should be much lower. A similar opinion is expressed by other authors. Thus, it is believed ${ }^{51,52}$ that "substrate (futile) cycles in the tissue of normal animals consume less than 5\% of ATP. This share, according to Katz and Rogenstad ${ }^{51}$ is less at carbohydrate diet. Kummel ${ }^{52}$ takes the view that "substrate cycle" of PFK/FBP functions in the tissues is fairly stable at different rates of gluconeogenesis and that it is not a universal mechanism for metabolism regulation in tissues. Another substrate cycle, a triglyceride/fatty acid is considered an important in the regulation of the oxidative metabolism of lipids ${ }^{50}$ and is also associated with the utilization of ATP. According to experimental data, substrate cycles in vivo are close to equilibrium state. Consequently, these cycles can proceed without dissipating of ATP energy in the form of heat. ${ }^{50,53}$

\section{The phenomenon of aerobic activity}

Bennett, Ruben ${ }^{8,16}$ at interpretation of the nature of homeothermia, pay more attention to the phenomenon of "activity" of aerobic metabolism. In particular, the authors believe that the warmbloodedness is due to high aerobic metabolism. The level of which is up to 5-10 times higher than in cold-blooded animals under the same conditions of body temperature of compared animals. According to them, aerobic activity is the basis for increasing the body's energy needed for the rapid locomotion movement of mammals ${ }^{54}$ and for birds' flight. ${ }^{16}$ Discussing the role of possible factors contributing to phenomenon "activity" Bennett ${ }^{8}$ considers that such factors as the activation of aerobic metabolism, the evolution of the blood circulation and respiratory system in vertebrates, as well as an increase in the concentration of mitochondria are of great importance. In some works $^{55,56}$ the lung surface was studied and data were obtained that it correlated with the intensity of animal metabolism. Great importance is also attached to the blood flow as a factor, which determines the effectiveness of the metabolism, because in warm-blooded animals its rate is several times higher than in cold-blooded ones. ${ }^{57,58}$ 
It was also suggested that in the evolution of warm-blooded animals, the number of mitochondria and their density in tissues increase. However, according to Savina ${ }^{59}$ many cold-blooded animals living in water with low oxygen content have a large number of mitochondria in tissues. Consequently, the number of mitochondria can participate in different processes. It must be said that the abovementioned systems of warm-blooded animals are most likely intended to maintain tissue metabolism, particularly on the cellular and mitochondrial level. The above mentioned facts show that the efficiency of many energetic processes in an organism is high. To suppose that the endothermy of an organism is due to the heat formation at the expense continually (and low efficiency) flow of energetic processes is a little grounded point of view. Against this point of view comes the fact of the existence of cold-blooded animals, in the organism of which the energetic processes are also continually proceeding. However, they have relatively lower metabolism intensity than in warm-blooded animals. These assumptions allow us to think that the warm-bloodedness can be caused by a special system of heat production that has arisen in these organisms during the evolution process.

\section{Proton leak, uncoupling respiration of mitochondria and thermogenesis}

In consideration of close relationship of subcellular mechanisms with thermogenesis, a number of studies have been carried out in this direction using biochemical, biophysical and genetic approaches. In general, experimental works were carried out at the mitochondrial and cellular levels, and in some works using endo- and ectothermic organisms. One of the important approaches in this direction is study of the proton leakage process of mitochondria caused by increased permeability of their inner membrane. Proton leakage is caused by specific membrane proteins-uncouplers (uncoupler proteins-UCPs) localized in internal mitochondrial membranes. To this day, several species of proteins have been identified in various tissues, which are designated as UCP1, UCP2, UCP3and UCP4.$^{60}$ They contribute to the dissemination of the proton gradient on the mitochondrial membrane, which was created by the energy of substrates oxidation. Dissemination of the proton gradient is a source of biological heat, providing heat production of endothermic organism. ${ }^{61,62}$ Protons leak through the pores of UCPs occurs at high membrane potential of mitochondria and has a non-ohmic connection to the membrane conductivity. ${ }^{61}$ Gradual reduction of the membrane potential simultaneously reduces proton leakage that could improve the ATP synthesis. According to the opinion of the researchers of this problem, proton leakage as a whole can occupy about $25-40 \%$ of the total respiration rate of mitochondria and, accordingly, of the organism. We think that this value is quite low, as the heat production in the endothermic organisms can be spent up to $90 \%$ of the total energy. It is possible to admit the existence of a part of respiration of mitochondria independent of the membrane potential. In particular, high uncoupling respiration is realized in mitochondria of brown fat at oxidation of various substrates. ${ }^{63-66} \mathrm{It}$ is particularly high $\mathrm{V}_{4}$ in the oxidation of succinate, not suppressed by oligomycin and carboxyatractyloside. Earlier high uncoupling respiration was found during NADH oxidation in mitochondria of skeletal muscles ${ }^{67-74}$ it was found uncoupled ATPase, which may be near to the problem of thermogenesis.

A comparison was carried out in the phylogeny of different groups of animals. In reptiles it has been found that proton leakage in hepatocytes and their mitochondria is lower than in mammals, although the difference is insignificant. ${ }^{75}$ These data, in together with others ${ }^{76}$ were poorly consistent with the idea of the thermogenic role of UCPs in the organism. Therefore it was studied the possibility that the ANT anion-translocator is plays the important role in tissues of thermogenesis. Thus, at comparison of endo-and ectothermic organisms, it has been shown that the value of proton conduction is well correlated with the amount of mitochondrial anion carriers, in particular, with the amount of adenine nucleotide-translocase (ANT). ${ }^{77,78}$ accounting for $75 \%$ of basal proton leakage. Definite contribution up to $8 \%$ is also made by the UCP1-uncoupling protein of mitochondria of brown fat. It is suppose that the ANT does not determine the entire basal proton leakage (resting metabolism), since neither carboxyatractyloside (inhibitor of ANT) nor GDP (inhibitor of UCPs) significantly suppress the proton leakage process, so participation of other mitochondrial anion-translocators is also possible.

These representations are substantiated by an experimental comparison of the proton conductivity of hepatocytes in mammalian and reptilian. In the latter, the rate of oxygen consumption is 4-5 times weaker, which correlated with a 4-fold lower level of ANT in reptiles. Therefore, the amount of ANT in the mitochondria of mammalian hepatocytes is considered to be an important modulator of thermogenesis at the cellular level. ${ }^{79}$ It should also be noted that in these examined works it is believed that all populations of mitochondria participate in the proton leakage process that passes through several stages ${ }^{80}$ A number of works indicate that the contribution of proton leakage in many tissue metabolism is about $25 \%$, and skeletal muscle level reaches up to $50 \%$. It is desirable to continue studies in this regard but this contribution does not explain the difference of metabolism between endo- and ectothermic organisms, differing in the range of 10 times ( or higher) in standard metabolism.

It has been demonstrated a participation of the UCPs in thermoregulation, obesity, diseases, aging, as well as in the regulation of the superoxide level. ${ }^{81,82}$ In this group of investigations of proton leakage, as a substrate for oxidation are used separate ones (mainly succinate). The obtained value of the proton leakage may incriese energy expendsure about $25 \%$. In our opinion, it is not sufficient for the heat production necessary to maintain the endothermy of the organism. Another option for solving the problem of biological thermogenesis is carried out at the mitochondrial and cellular levels using other variations of the methodological approaches, which allowed considering the mitochondrial path of thermogenesis from other positions. In these studies, isolated mitochondria from different tissues of endo-and ectothermic animals were used. To briefly outline the general picture of the research we describe here the results obtained on mitochondria and rat heart cells (cardiocytes). In this series of investigation existence in tissues two types of mitochondria is discussed; one of them couple with the ATP synthesis, second type is not couple und fulfill thermogenic function. It is important to note that the mitochondrial oxidation substrates were exogenous succinate, NADH (+ cytochrome c), ascorbate (+ cytochrome c). Firstly it must be said that NAD-dependent substrates (glutamate, malate+pyruvate) were oxidized in these tissue preparations with large respiratory control $\left(\mathrm{RC} \mathrm{V}_{3} / \mathrm{V}_{4}\right)$. Specific features of the oxidation of the first three substrates were interesting. Thus, at succinate the rate of respiration occurred at an increased rate of $\mathrm{V}_{4}$. This widely known fact is interpreted by us as a sign of its oxidation simultaneously in two types of mitochondria, coupled and uncoupled with ATP synthesis. Such explanation was confirmed by an analysis of the nature of the oxidation 
of other substrates. It turned out that exogenous NADH (+cytochrome c) and ascorbate (+ cytochrome c) are oxidized intensively both by preparations of isolated mitochondria and cellular preparations. ${ }^{69,70,83,84}$ The process proceeds without the phosphorylation of added ADP, so as oligomycin or carboxyatactyloside don't affect the dynamics of their oxidation. Moreover, respiration is inhibited by rotenone $(1 \mu \mathrm{g} /$ $\mathrm{ml}$ ) by about $90 \%$ on the first substrate and by sodium cyanide $(1 \mathrm{mM})$ in all substrates. Consequently, their oxidation occurs along the main mitochondrial respiratory chain.

Obtained results allowed to postulate that in the studied preparations of tissues contain not only phosphorylating, but also non-phosphorylating (noncoupled) mitochondria. The biological function of noncoupling respiration may be heat production, as previously shown a weak expression of this form of respiration in cardiac and liver mitochondria of cold-blooded frog. ${ }^{84}$ It is also shown that in mitochondria of warm-blooded rats uncoupling respiration is higher in heart mitochondria than in the liver ones. In our model of respiration ${ }^{84}$ there is a group of uncoupled mitochondria, along with a group of phosphorylating ones, which makes it possible to explain the features of the oxidation of different substrates in the suspension of mitochondria and cells. In addition, even if the amount of noncoupled mitochondria in the suspension is about $50 \%$, this will not significantly affect the total membrane potential of the mitochondrial suspension and reduce its value by approximately $18 \%$ according to Nernst formula. In conclusion, it can be said that the study of thermogenesis problem in endothermic organisms has a complex history. How could nature transfer the animal's organism from cold-blooded to warmblooded? How could it raise the level of basic metabolism to ten or more times? More possibly, an important transformation occurred in evolution at the level of mitochondria of tissues a creation of proton leakage system and in non-coupled mitochondria (along with phosphorylating ones) in the tissues of mammals and birds.

It should be said that our concept of uncoupling respiration of mitochondria differs from the literary one. However, it is possible to find a common side for the last two views, which talk about proton leakage and uncoupled respiration of mitochondria. In our opinion, the common side for them is proton leakage. Our view postulates the existence of two types of mitochondria. One of them synthesizes ATP, while the other type has a high membrane permeability for many substrates and carries out proton leakage during oxidation of different substrates. According to our hypothesis the UCPs may be located in second type of mitochondria. Unfortunately, our published scheme ${ }^{84}$ has not been discussed so far in the modern literature. In our opinion, testing our results by other researchers could help to discuss ideas and solve a number of difficulties that arise in this direction.

\section{Acknowledgments}

None.

\section{Conflicts of interest}

The author declares there is no conflicts of interest.

\section{References}

1. Moberly YR. The metabolic responses of the common Iguana, to walking and diving. Comp Biochem Physiol. 1968;27:21-32.

2. Taylor CR, Schmidt Nielsen K. Energetic cost of running. Physiologist 1969:12:372.
3. Taylor CR, Schmidt Nielsen K, Roab JL. Scaling of the energetic cost of running to body size in mammals. Am J Physiol. 1970;219(4):1104-1107.

4. Tucker VA. Energetic cost of locomotion, in animals. Comp Biochem Physiol. 1970;34(4):841-846.

5. Bakker RN. Locomotors energetic of Lizards and Mammals compared. Physiologist. 1972;15:76.

6. Schmidt Nielsen K. Locomotion: Energy cost of swimming, flying and running. Science. 1972;177(4045):222-228.

7. Prosser L. Temperature comparative physiology of animals. Moskva Mir. 1977;2:84-209.

8. Bennett AF, Buben JA. Endothermy and activity in Vertebrates. Science. 1979;206:649-654.

9. Krogh A. The respiratory exchange of animals and man. 1916;151-168.

10. Hemmingsen PW. Energy metabolism as related to body size and respiratory surface and its evolution. Rep Steno Hosp. 1960.

11. Schmidt Nielsen K. The sizes of animals: why are they important? Moskva Mir. 1987.

12. Kern JM. Metabolic rate of the insect brain in relation to body size and phylogeny. Comp Biochem Physiol. 1985;81(3):501-506

13. Heusner AA. Energy metabolism and body size. 1. Is the 0,75 mass exponent of Kleiber's equation a statistical artificial? Respir Physiol. 1982;48(1):1-12

14. Hulbert AJ, Else PL. Comparison of the mammal machine and reptile machine energy use and thyroid activity. Am J Physiol. 1981;241(5):350 356.

15. Dolnik VR. Bioenergetics of modern animals and the origin of homeothermia. J obsh biol. 1981;42:60-74.

16. Smith CL. The temperature dependence of oxidative phosphorylation and of the activity of various enzyme systems in liver mitochondria from coldand warm-blooded animals. Comp Biochem Physiol. 1973;46(3):445-461.

17. Lehninger A. Biochemistry. Moskva Mir. 1974.

18. Lehninger AL. Bioenergetics. NY Amsterdam. 1965

19. Marshall E. Biophysical chemistry. Principles, techniques and applications. 1976.

20. Racker E. Mechanism in Bioenergetics. 1965.

21. Prusiner S, Poe M. Thermodinamic considerations of mammalian thermogenesis. Nature. 1968;220:235-237.

22. Hochachka PW. Regulation of heat production at cellular level. Fed Proc. 1974;33(10):2162-2169.

23. Hochachka PW, Somero GN. Biochemical Adaptation.1984.

24. Weech RL, Raijman L, Krebs HA. Equilibrium relations between the cytoplasmic adenine nucleotide system and nicotine amide-adenine nucleotide system in rat liver. Bioche J. 1970;117:459-503.

25. Slater EC, Rosing J, Mol A. The phosphorylation potential generated by resting mitochondria. Biochem Biophys Acta. 1973;292:534-553.

26. Whitmer JT, Idell Wenger JA, Rovetto MJ, et al. Control of fatty acid metabolism is ishemic and hypoxic hearts. $J$ Biol Chem. 1978;253(12):4305-4309.

27. Wilson DF, Erecinska M, Leslie Dutton. Mitochondrial electron transport and energy conservation. Acc Chem Res. 1972;5(7):234-241.

28. Hassinen IE, Hiltunen K. Respiratory control in isolated perfused rat heart. Biochem Biophys Acta. 1975;408(3):319-330. 
29. Wilson DF, Dulton PL. Thermodinamic control of mitochondrial energy coupling. Energy metabolism and the regulation of metabolic processes of Mitochondria. Acad Press NY London. 1972.

30. Lemasters JJ. The ATP-to-oxygen stoichiometries of oxidative phosphorylation by rat liver mitochondria. An analysis of ADP-induced oxygen jumps by linear nonequilibrium thermodynamics. $J$ Biol Chem. 1984;259(21):13123-13130.

31. Hommes P, Drost Y, Geraets F, et al. The energy requirement for growth amplication of Atkinson's metabolic price system. Pediatrics Rev $1975 ; 9: 51-55$

32. Spady DW, Payne PR, Picou D, et al. Energy balance during recovery from malnutrition. Am J Clin Natr. 1976;29(10):1073-1088.

33. Coulson RA, Hernandez T. Alligator metabolism. Studies on chemical reactions in vivo. 1983 .

34. Verenikov AA. Potential difference on cells with stationary ion distribution Guide to cytology. Nauka. 1966;2:22-46.

35. Whittam R. The interdependence of metabolism and active transport. The Cellular functions of Membrane Transport. New Jersey. 1964.

36. Willis JS. The interaction of $\mathrm{K}+$, ouabain and $\mathrm{Na}+$ on the cation transport and respiration of renal cortical cells of hamsters and ground squirrels. Biochem Biophys Acta. 1968;163(4):516-530.

37. Ismail Beigi P, Edelman IS. Mechanism of thyroid calorigenesis. Role of active sodium transport. Proc Natl Acad Sci US A. 1970;67(2):1071-1078.

38. Ismail Belgi P, Melman IS. Effects of thyroid status on electrolyte distribution in rat tissues. Am J Physiol.1973;225(5):1172-1177.

39. Asano Y, Liberman VA, Edelmann IS. Thyroid thermogenesis genesis: relationships between $\mathrm{Na}$-dependent respiration and $\mathrm{Na}$, K-ATPase activity in rat sceletal muscle. J Clin Invest. 1976;57:368-578.

40. Asano Y. Increased cell membrane permeability to $\mathrm{Na}^{+}$and and $\mathrm{K}^{+}$ induced by thyroid hormone in rat skeletal muscle. Experientia Suppl. 1978;32:199-203.

41. Van Rassum GD. On the coupling of respiration to cation transport in slices of rat liver. Biochim Biophys Acta. 1970;205(1):7-17.

42. Zorov DB, Mokhova EN. On the connection of thermogenesis of muscles and transport Na, K-ATPase. Mitochondria Moskva: Nauka. 1973;100 105 .

43. Creese R. Sodium flukes in diaphragm muscle and the effects of the insulin and serum proteins. J Physiol. 1968;197:225-278.

44. Chinet A, Clausen T, Girardier L. Microcolorimetric determination of energy expenditure due to active sodium- potassium transport in the soleus muscle and brown adipose tissue of the rat. J Physiol. 1977;265(1):43-61.

45. Clausen T, Hansen O. The Na, K-pump energy metabolism and obersity. Biochem Biophys Res Comm. 1983;104:357-562.

46. Barton L, Edholm. Human in cold conditions. 1957.

47. Dolnik VR. Energy exchange and evolution of animals. 1968.

48. Newsholam EA, Crabtree B. Substrate cycles in metabolic regulation and in heat generation. Biochem Soc Symp. 1976;(41):61-109.

49. Newsholm E, Start K. Regulation of metabolism. 1977.

50. Katz J, Rognstad R. Futile cycling in glucose metabolism. Trends in Biochemical Sciences. 1978;3(3):171-174.

51. Kummel L. Glucose and fructose-6-phosphatase cycling by rat hepatocytes at gluconeogenesis. Acta Univ Carol Med (Praha). 1981;27(7-8):477-490.
52. Knight BL, Myant NB. A comparison between the effects of cold exposure in vivo and of noradrenaline in vitro on the metabolism of the brown fat of new-born rabbits. Biochem J. 1970;119:103-111.

53. Bennett AF. A comparison of activities of metabolic enzemes in Lizards and rats. Comp Biochem Physiol. 1972;42(4):637-647.

54. Tenney SM, Remmers JE. Comparative quantitative morphology of the mammalian lung. Diffusing area. Nature. 1963;197:54-56.

55. Coulson PA, Hernandez T. Alligator metabolism. Studies on chemical reactions in vivo. 1983 .

56. Stahl WR. Scaling of respiratory variables in mammals. J Appl Physiol. 1967;22(3):453-460.

57. Ultsch CR. A theoretical and experimental investigation of the relationship between metabolism, body size and oxygen exchange capacity. Resp Physiol. 1973;18:143-160.

58. Savina MV. Adaptive mechanisms of tissue respiration in vertebrate evolution. Nauka Saint Petersburg. 1992.

59. Bouillaud F, Couplan E, Pecqueur C, et al. Homologues of the uncoupling protein from brown adipose tissue (UCP1): UCP2, UCP3, BMCP1, UCP4? Biochim Biophys Acta. 2001;1504(1):107-119.

60. Brand MD. Uncoupling to survive? The role of mitochondrial inefficiency in aging. Exp Gerontol. 2000;35(6-7):811-820.

61. Clarce A, Porter HO. Temperature, metabolic power und the evolution of endothermy. Biol Rev Camb Philos Soc. 2010;85(4):703-727.

62. Grav HJ, Pederson JI, Christiansen EN. Condition in vitro which affect respiratory control and capacity for respiration linked phosphorylation in brown adipose mitochondria. The FEBS Journal. 1970;12(1):11-23.

63. Skaane, Christiansen EN, Pedersen JI, et al. Oxidative properties of brown adipose tissue mitochondria from rats, guinea-pigs and hedgehogs. Comp Biochem Physiol B. 1972;42(1):91-107.

64. Nedergaard J, Cannon B. Thermogenic Mitochondria, Bioenergetics. 1984.

65. Akhmerov RN, Allamuratov ShI. The warm-bloodedness of organism and its energetic mechanisms. 1994.

66. Blanchaer MC. Respiration of mitochondria of red and white skeletal muscle. Am J Phyziol. 2017.

67. Blanchaer MC, Lundquist CG, Griffith TJ. Factors influencing the utilization of reduced nicotinamide adenine dinucleotide by pigeon heart mitochondria. Can J Biochem. 1966;44(1):105-117.

68. Akhmerov RN. Tissue respiration, energy production and heat production in different rat tissues. 1981

69. Akhmerov RN. The tissue oxidation and nonphosphorylating pathway. 1983.

70. Rusmussen UF. The oxidation of added NADH by intact heart mitochondria. FEBS Letters. 1969;2(3):157-162.

71. Rasmussen UF, Rasmussen HN. The NADH oxidize (external) of muscle mitochondria and it role in the oxidation of cytoplasmic NADH. $J$ Biol Chem. 1985;229:631-641.

72. Nohl H, Schonheit K. The effect of the exogenous NADH dehedrogenase of heart mitochondria on transmembranous proton movement. Arch Biochem Biophys. 1996;331(2):259-364.

73. Chao DL, Davis EJ. Studies on the role of $\mathrm{Mg}^{2+}$ - and $\mathrm{Mg}^{2 *}$ - stimulated adenosine triphosphotase in oxidative phosphorylation. Biochemistry. 1972;11(10):1943-1952.

74. Hulbert AJ. Else PL, Manolis SC, et al. Proton leak in hepatocytes find liver 
mitochondria from archosaurs (crocodiles) and allometric relationship for ectotherms. J Comp Physiol B. 2002;172(5):387-97.

75. Duong CA, Sepulveda CA, Graham JB, et al. Mitochondrial proton leak rates in the slow, oxidative myotomal muscle and liver of the endothermic short finmako shark (Isurusoxyrinchus) and the ectothermic blue shark (Prionaceglauca) and leopard shark (Triakissemifasciata). J Exp Biol. 2006;209(Pt 14):2678-2685.

76. Brand MD, Pakay JL, Ocloo A, et al. The basal conductance of mitochondria depends on adenine nucleotide translocase. Biochem $\mathrm{J}$. 2005;392(Pt 2):353-362.

77. Jastroch M, Divakaruni AS, Mookerjee S, et al. Mitochondrial proton and electron leaks. Essays Biochem. 2010;47:53-67.

78. MD Brand, P Couture, PL Else, et al. Evolution of energy metabolism: proton permeability of inner membrane of liver mitochondria is greater in a mammal than in a reptile. Biocheml J. 1991;275(1):81-86.

79. Porter RK. Mitochondrial proton leak: a role for uncoupling proteins 2 and 3? Biochim Biophys Acta. 2001;1504(1):120-127.
80. Mark FC, Lucassen M, Portner HO. Thermal sensitivity of uncoupling protein expression in polar and temperature fish. Comp Biochem Physiol Part D Genomics Proteomics. 2006;1(3):365-374.

81. Brand MD, Buckingham JA, Esteves TC, et al. Mitochondrial superoxide and aging : uncoupling protein activity and superoxide production. Biochem Soc Symp. 2004;(71):203-213.

82. Kokoz YuM, Popov VN, Khunyan SS, et al. Features of energy-coupled respiration of cardiocytes. Molecular mechanisms and regulation of energy metabolism. Pushchino, Moskovsk. 1987;14-24.

83. Akhmerov RN. Quantitative difference in mitochondria of endothermic and ectothermic animals. FEBS Lett. 1986;198(2):251-255.

84. Akhmerov RN, Niyazmetov BA, Mirzakulov SO, et al. Coupled und noncoupled respiration in rat cardiocytes und mitochondria. European $J$ Biomedical and Pharmaceutical Sciences. 2016;3(12):8-16. 